\title{
Validation Study of the Korean Version of Early Years Toolbox (EYT)
}

\author{
Shunah Chung ${ }^{1}$, Inkyung $\mathrm{Kim}^{2}$, Heejin $\mathrm{Kim}^{3}$, Yumi Ma ${ }^{3}$, Boyoung Park ${ }^{3}$ \\ Professor, Division of Child welfare \& Studies, Sookmyung woman's university, Seoul, Korea ${ }^{1}$ \\ Research Fellow, Department of Public finance and Social policy, Korea Development Institute, Sejong, Korea ${ }^{2}$ \\ Ph. D. Student, Division of Child welfare \& Studies, Sookmyung woman's university, Seoul, Korea ${ }^{3}$

\section{한국판 Early Years Toolbox (EYT)의 타당화 연구 \\ 정선아 ${ }^{1}$, 김인경 ${ }^{2}$, 김희진 ${ }^{3}$, 마유미 ${ }^{3}$, 박보영 ${ }^{3}$ \\ 숙명여자대학교 아동복지학부 교수 ${ }^{1}$, 한국개발연구원 공공경제연구부 연구위원 ${ }^{2}$, 숙명여자대학교 아동복지학부 박사과정}

\begin{abstract}
Objectives: The aim of this study is to validate the Early Years Toolbox (EYT), which can measure executive function of children.

Methods: Participants in this study were 1973 to 5-years-old children in one kindergarten and two day care centers. An analysis of EYT's the construct validity, the concurrent validity, and reliability were performed.

Results: As a result, each tool has a reciprocal static correlation $(r=.22 \sim .41, p<.05)$ appeared to be present, indicating that there was no difficulty in assembling them into a single factor. Also, Mr. Ant and The Eight Boxes Task $(r=.19, p<.05)$, Go/No-Go and Lift Flag Task $(r=.28, p<.05)$, Not This and Dig it span - Backward $(r=.27, p<.05)$, Card Sorting and Dimensional Change Card Sort (DCCS) $r$ $=.57, p<.05)$, Expressive Vocabulary and Receptive and Expressive Vocabulary Test-Expressive $($ REVT-E) $(r=.66, p<.05)$, Numbers and Mathematical Ability Picture Test for Young Children $(r=.73$, $p<.05)$ all had significant correlation. However, it was impossible to confirm the correlation between Children's Social Behavior Questionnaire (CSBQ) and Preschool and Kindergarten Behavior Scales (PKBS). Finally, the EYT demonstrated high internal consistency, which enabled the verification of the reliability of the tool.

Conclusions: The Early Years Toolbox is a reliable and valid executive function instrument for children and is recommended for evaluating executive function.
\end{abstract}

Keywords: Early Years Toolbox, validation, executive function.

\section{Introduction}

인간은 삶을 살아가면서 해결해야 하는 새롭고 도전적인 많은 문제들을 마주하게 된다. 이러한 삶을 살아가면서 인간은 목 표지향적인 행동을 하고, 문제해결을 하기 위하여 의식적으로 사고하고, 자신의 행동을 조절할 수 있어야 한다(Y. Kim, 2018;

Corresponding Author: Boyoung Park, Ph. D. Student, Division of Child welfare \& Studies, Sookmyung woman's university, Cheongpa-ro 47-gil 100 , Yongsan-gu, Seoul, Korea

E-mail: bbooing@sookmyung.ac.kr
Sung, 2017). 이러한 인간의 특성에 영향을 미치는 능력이 실행 기능(executive function)이다. 실행기능이란 뇌의 전두엽에서 이 루어지는 고차원적 기능(Diamond, 2013; Do, Cho, Kim, Kim, \& Shin, 2010; Y. Kim, 2018; Welsh \& Pennington, 1988)으로서, 자신이 지향하고 있는 목표에 도달하기 위해 작업 기억의 과정 에 따라 방해자극을 억제하고 인지적으로 유연하게 사고하는

(C) The Korean Association of Child Studies

This is an Open Access article distributed under the terms of the Creative Commons Attribution Non-Commercial License (http:// creativecommons.org/licenses/by-nc/4.0) which permits unrestricted noncommercial use, distribution, and reproduction in any medium, provided the original work is properly cited. 
능력을 의미한다(Diamond, Barnett, Thomas, \& Munro, 2007).

최근 뇌 발달 연구가 활발해지면서 영유아의 실행기능에 관한 연구는 더욱 지지를 받고 있다. 이에 따르면 영유아의 실 행기능은 이후 상급학교에서의 수학과 언어 능력을 모두 예 측할 수 있다(Blair \& Razza, 2007). 나아가 실행기능은 이후 성 인이 되어서 직업을 구하고, 지속하여 일을 할 수 있는 것에도 작용하여 결국 개인의 삶의 질에 영향력을 갖는 요인이라 할 수 있다(Bailey, 2007; Davis, Marra, Najafzadeh, \& Lui-Ambrose, 2010). 실행기능이 유아의 현재뿐 아니라 미래의 삶에 영향을 미친다는 점은, 앞으로 영유아기 실행기능에 관한 연구는 더 욱 증가할 것으로 보인다.

이러한 실행기능은 실행기능을 관장하는 전두엽, 특히 전 전두엽의 활성화 정도에 따라 '인지적 실행기능(cool executive function)'과 '정서적 실행기능(hot executive function)' 두 가지 로 나뉘어 연구되고 있다(Zelazo \& Muller, 2004). 먼저, "인지 적 실행기능'은 상대적으로 인지적 능력이 요구되는 실행기 능으로 추상적이고 탈맥락적인 과제를 수행할 때 좀 더 활성 화 된다(Zelazo \& Muller, 2004). 인지적 실행기능을 구성하 고 있는 핵심 능력은 억제, 작업 기능, 인지적 유연성 등이다 (Diamond, 2013). 억제는 목표 행동을 달성하기 위해 불필요 한 자극을 무시하고, 부적절한 행동을 통제하는 능력을 의미 한다(Diamond, 2013; Howard \& Melhuish, 2017). 작업 기능은 일시적으로 관련 정보를 유지하고 처리하는 기억 용량에 대한 것이다(Diamond, 2013; Howard \& Melhuish, 2017; W. Lee \& Cheung, 2018). 인지적 유연성은 문제를 해결하기 위한 접근 방식을 변화시키고 새로운 요구, 규칙 등에 다양한 대안을 생 각하면서 융통성 있게 생각하는 능력이다(Diamond, 2013; Do et al., 2010; Howard \& Melhuish, 2017).

두 번째, ‘정서적 실행기능’은 '인지적 실행기능'에 비해 동 기 및 정서가 유발되는 맥락적 상황에서 작동하는 실행기능 으로서(Zelazo \& Muller, 2004), 욕구, 소망, 바람과 같은 재 적 동기가 포함된 상황에서 유발된다(Cunningham \& Zelazo, 2007). 정서적 실행기능은 유아의 자기조절 능력과 사회-정 서 발달 간에 밀접한 연관성이 있을 뿐 아니라(Sethi, Mischel, Aber, Shoda, \& Rodriguez, 2000), 유아의 외적 문제 행동과 내 적 문제 행동에도 영향을 주는 주요한 변인이다(Riggs, Blair, \& Greenberg, 2003). 또한 또래와 공동의 목표를 달성하기 위해 욕구를 조절하는 친사회적인 행동에 직접적으로 영향을 주기 도 한다(Diamond, 2013; Peake, Hebl, \& Mischel, 2002).

영유아의 실행기능은 이미 널리 알려져 있듯이 영유아의 주의 집중 능력 발달에 영향을 미치는 요인이다(Chi \& Kim;
2016; M. R. Song \& Ha, 2014). 뿐만 아니라 영유아기의 자 아존중감 형성과(Chi \& Baik, 2016) 애착 형성과도 관련된다 (Bernier, Carlson, Deschenes, \& Matte-Gagne, 2012). 또한 실행 기능은 영유아의 정서 발달과 관계되어 있을 뿐 아니라 유아 의 학교 준비도에도 작용하는 요인이다(Blair \& Razza, 2007; Morrison, Ponitz, \& McClelland, 2010). 취학 후 유아의 수학 능력, 문해력에도 영향을 미친다(Borella, Carretti, \& Pelegrina, 2010).

아동발달에 이러한 영향을 미치는 실행기능의 측정은 인지 적 실행기능과 정서적 실행기능으로 나뉜다. 본 연구에서는 인지적 실행기능에 초점을 맞추어 그 타당도를 검증하고자 한 다. 이에 인지적 실행기능을 측정하기 위해 사용되는 도구들 을 살펴보면 다음과 같다. 인지적 실행기능 중 억제를 측정하 는 도구로는 실행기능은 색과 행동에 대하여 검사자가 명령한 대로 따라하거나 혹은 명령과 반대로 수행하기 하는 '해와 달 과제(Gerstadt, Hong, \& Diamond, 1994)', '토끼와 호랑이(양과 사자/ 착한 인형 나쁜 인형)(Kochanska, Murray, Jacques, Koenig, \& Vandegeest, 1996)', ‘스트룹 검사(Stroop, 1935)'가 있다(Chi \& Baik, 2016; H.-J. Kim \& Hong, 2011; Kong \& Lim, 2013; K. Lee \& Lee, 2017; K.-S. Park, 2018; Shin, 2005; Sung, 2017). 인지 적 유연성 측정 도구로는 '색'과 '모양'을 구분하는 인지적 전 환 능력을 측정하기 위한 '카드분류과제(Zelazo, 2006)'가 우 리나라 실행기능 연구에서 가장 대표적으로 사용된다(Cha, 2015; Chi \& Baik, 2016; K.-S. Park, 2018; Shin, 2005; Sung, 2017). 작업 기억은 유아가 숫자 혹은 위치를 기억하고 말하거 나 찾아보도록 하는 '8개 상자 과제(Hughes, 1998)', '코시블록 과제(Kessels, Van Zandvoort, Postma, Kappelle, \& Haan, 2000)', '숫자 거꾸로 따라 말하기 검사(K-WISC- II)'를 많이 사용하고 있다(Cha, 2015; Kong \& Lim, 2013; K. Lee \& Lee, 2017; K.-S. Park, 2018). 이렇듯 인지적 실행기능을 측정하기 위해서는 각 요소를 측정하는 도구를 사용해야 한다.

위에서 언급된 것과 같이 인지적 실행기능을 측정하기 위 해서는 단일 도구를 사용할 수 없고, 이는 인지적 실행기능 검 사의 한계점으로 작용하고 있다. 그 한계점을 살펴보면 다음 과 같다. 실행기능은 여러 신경 심리 검사로 면대면으로 측정 되어야 하므로 검사자를 대상으로 검사 시행과 채점을 위한 훈련, 검사자 간의 신뢰도를 확보하기 위한 교육 등이 요구된 다(Do et al., 2010). 또한 동일한 훈련을 받은 검사자라고 할지 라도 유아의 능력을 가장 효과적으로 포착하기 위해 필요한 조치, 자극, 시기, 지침이 언제 이루어지는 것이 가장 적절한지 에 대한 합의가 이루어지고 있지 않아, 검사자 개인간의 차이 
가 측정 결과에 영향을 미치게 된다(Blair, Zelazo, \& Greenberg, 2005). 면대면 측정의 한계를 해결하기 위하여 인터넷을 기 반으로 한 컴퓨터 프로그램을 개발하여 실행 기능 검사를 실 시하기도 하였다(Do et al., 2010). 유아가 이어폰을 통해 수행 방법을 들은 후, 컴퓨터 키보드를 활용하여 정답을 맞히는 방 법은 직관성을 떨어뜨려 정확한 평가를 방해하며, 특히나 이 어폰, 컴퓨터 키보드 등의 사용이 익숙하지 않은 유아의 경 우 그것에 능숙해 지는 시간을 필요로 하기 때문에 측정 결과 를 일반화시키기 어렵다는 한계를 지니는 것으로 나타났다 (Howard \& Okely, 2015).

실행기능 검사의 또 다른 한계는 실행기능의 하위 구성요 소를 측정하는 도구가 다양하여 각 구성요소를 측정하는 검 사도구들 간의 신뢰도를 검증하기 어렵다는 점이다(Howard $\&$ Melhuish, 2017). 앞서 설명하였듯이 인지적 실행기능의 경 우 각각 구성 요소를 측정하는 도구들은 여러 가지 이다. 예를 들어 '억제'를 측정하는 도구라고 할지라도 '착한인형, 나쁜인 형' 과제는 단순히 착한인형이 말하는 것은 수행하고, 나쁜 인 형이 말하는 것은 수행하지 않는 것으로 억제를 측정한다. 그 리고 '그림카드' 의 경우 검사자가 '달' 카드를 보여주면 유아 는 '낮’이라고 말해야 하고, '해’카드를 보여주면 유아는 '밤’이 라고 말하는 반대로 대답하는 것으로 억제능력을 측정하고 있 다. '스트룹검사'의 경우 유아가 색을 보고 단순히 색깔을 말하 는 색깔과제, 여러 가지 색깔로 된 글자를 보고 글자를 말하는 글자과제, 색깔 이름이 써진 글자와 글자의 색깔이 일치하지 않는 조건에서 색깔을 말하는 방해과제의 3 가지 과제 모두 각 각 반응시간(reaction time)과 오류반응 수로 억제능력을 측정 한다. 이렇듯 각 도구의 억제를 측정하는 내용은 수준 차이가 있고, 이에 따라 검사자 개인이 억제능력을 측정하기 위해 어 떤 도구를 사용 하는가 뿐만 아니라 영유아가 도구를 이해하 는 능력이 억제능력에 영향을 미칠 수밖에 없다. 마지막으로 다수의 영유아를 대상으로 하는 대규모 연구에서는 시간적, 비용적 제약이 실행기능 검사 연구를 수행하기 어렵도록 한 다. 이러한 문제점을 고려한다면 연구 결과의 신뢰도, 타당도 는 물론 연구의 효율성을 높일 수 있는 측정 도구가 필요하다.

이러한 실행기능 측정의 한계점을 해결한 도구가 개발되었 다. Howard와 Melhuish (2017)는 검사자 간 측정 변수를 최소 화하고, 면대면 검사의 시간적 문제 해결, 실행 기능 이외의 유 아의 능력이 검사 점수에 작용하는 것을 최소화할 수 있는 아 이패드 기반 어플리케이션(Early Years Toolbox [EYT])을 개발 하였다(Howard \& Melhuish, 2017). EYT는 총 7가지 항목으로 구성되어 있다. 그 중 네 가지 항목은 인지적 실행기능에 해당
하는 것으로 시·공간 작업 기억을 측정하는 $\mathrm{Mr}$. Ant, 음운론적 작업 기억을 측정하는 Not This, 억제를 측정하는 $\mathrm{Go} / \mathrm{No}-\mathrm{Go}$, 인지적 유연성을 측정하는 Card Sorting으로 구성되어 있다. 또한 EYT 애플리케이션에는 표현 어휘를 측정하는 Expressive Vocabulary, 수학능력을 측정하는 Early Numeracy와 교사에 의해 보고되는 Child Self-regulation \& Behavior Questionnaire $(\mathrm{CSBQ})$ 검사가 포함되어 있다. 인지적 실행기능 이외에 세 가 지 항목이 EYT에 포함 된 이유는 인지적 실행기능의 경우, 유 아의 학습관련 행동, 읽기 및 수학점수(Blair \& Razza, 2007)와 문제행동(McGlamery, Ball, Henley, \& Besozzi, 2007) 간의 높은 상관관계를 나타내기 때문이다.

Howard와 Melhuish (2017)는 호주 유아 1,764명을 대상으 로 EYT 어플리케이션의 타당화 연구를 진행하였다. EYT 어 플리케이션과 National Institute of Health의 'Flanker task' 등과 같은 실행기능 측정 검사와 'British Ability Scales' 등을 실시하 여 EYT의 신뢰도와 타당도를 검증하였다. 그 결과 매우 높은 신뢰도, 각 어플리케이션 간 상관을 통한 구인타당도와 기존 의 검사 도구와의 상관을 보이며 공인타당도를 확보하였다. 즉, EYT의 타당성을 밝히며, 유아관련 연구 및 교육적 적용을 가능하게 하여 유아의 실행기능을 객관적으로 측정할 수 있는 기회를 제공하였다.

실행기능의 중요성이 부각되고 있는 현 시점에서 영유아의 실행기능에 대한 활발한 연구를 위하여 Howard와 Melhuish (2017)가 개발한 EYT의 한국판 보급이 필요하다. 이에 본 연 구의 목적은 Howard와 Melhuish (2017)가 개발한 EYT를 한국 어로 번안하여, 한국형 아이패드 기반 실행 기능 검사 도구에 대한 타당도 및 신뢰도를 검증하는 것이다. 이에 따른 연구문 제는 다음과 같다.

\section{연구문제 1}

한국형 아이패드 기반 EYT의 타당도는 어떠한가?

1-1. 한국형 아이패드 기반 EYT의 내용타당도는 어떠한가?

1-2. 한국형 아이패드 기반 EYT의 구인타당도는 어떠한가?

1-3. 한국형 아이패드 기반 EYT의 공인타당도는 어떠한가?

\section{연구문제 2}

한국형 아이패드 기반 EYT의 신뢰도는 어떠한가? 


\section{Methods}

\section{연구대상}

본 연구 대상은 경기도에 소재한 두 곳의 어린이집과 한 곳의 유치원에 소속된 유아 197명이었다. 그러나 모든 항목에 자료 로 가용할 수준의 응답을 한 유아는 총 143 명이며, 연령별 남 아 및 여아의 인원과 비율은 Table 1 에 제시된 바와 같다.

Table 1

Demographic Characteristics of Participants

\begin{tabular}{|c|c|c|}
\hline Age & Gender & $n(\%)$ \\
\hline \multirow[t]{2}{*}{3} & Boy & $15(10.5)$ \\
\hline & Girl & $19(13.3)$ \\
\hline \multirow[t]{2}{*}{4} & Boy & $30(21.0)$ \\
\hline & Girl & $26(18.2)$ \\
\hline \multirow[t]{2}{*}{5} & Boy & $30(21.0)$ \\
\hline & Girl & $23(16.1)$ \\
\hline
\end{tabular}

Note. $N=143$

\section{연구도구}

\section{Early Years Toolbox (EYT) 앱}

EYT는 Howard (2017)와 그의 동료들이 개발한 아이패드기 반 어플리케이션으로 인지적 실행기능 검사 4종(Mr. Ant, Not This, Go/No-Go, Card Sorting)과 교사에 의해 설문 보고되 는 정서적 실행기능 검사 1종(Child Self-regulation \& Behavior Questionnaire [CSBQ]), 그 외에 Expressive Vocabulary, Early Numeracy 등 총 7종으로 구성되어 있다.

Mr. Ant 'Mr. Ant'는 인지적 실행기능 중 시.공간의 작업 기 억(visual-spatial working memory)을 측정하는 것으로, 개미 그 림에 붙은 스티커를 기억하고 그 자리에 스티커를 붙이는 실 험이다. 총 8 단계로 이루어져있으며 단계 별로 기억해야 하는 스티커의 개수가 $1-8$ 개로 늘어난다. 각 단계별 3개의 과제가 주어지며, 3 개의 과제를 모두 수행하지 못하였을 때 다음 단계 로 넘어가지 않고 점수가 계산된다. 유아에게 부여되는 점수 총 0-24점이다. 점수가 높을수록 시.공간 작업 기억이 높은 것 을 의미한다.

Not This 'Not This'는 인지적 실행기능의 음운론적 작업 기 억(phonological working memory)을 측정하는 것으로, 음성의 지시에 따라 모양을 찾는 과제이다. 1-8단계로 이루어져 있으 며, 1 단계에서는 유아에게 '빨간 색이 아닌 모양 찾기'(단일 기 능 - 빨간 색을 기억하기 위해)를 요청하나, 점차 단계가 올라 갈수록 복잡한 과제를 요청한다(빨간색이 아니고 크지 않은 것, 네모가 아니고 작지 않은 것 등). 각 단계는 5 개의 과제로 구성되어 있으며, 5 개의 과제 중 최소 3 개를 맞히지 못하면 다 음 단계로 넘어갈 수 없다. 1 단계에서 시작하여 5 개의 과제 중 최소 3 개를 정확하게 수행하면 각 단계별로 1 점을 부여하고, 그 이후의 성공 과제들은 $1 / 5$ 의 점수를 더한 것으로 계산한다. 점수가 높을수록 음운론적 작업 기억이 높은 것을 의미한다.

Go/No-Go 'Go/No-Go'는 인지적 실행기능의 억제(inhibition)를 측정하는 어플리케이션이다. 화면에 물고기가 나왔을 때에는 화면을 두드려 물고기를 잡고, 상어가 나왔을 때에는 두드리지 않아 상어를 잡지 않는 과제이다. 물고기와 상어의 비율이 8:2로 구성되어 물고기가 상대적으로 많아, 상어가 나 왔을 때 행동을 억제하는지 파악할 수 있다. 총 75 개의 과제가 1 초 혹은 1.5 초 간격으로 제시된다. $\mathrm{Go} / \mathrm{No}-\mathrm{Go}$ 의 경우 유아가 물고기를 잡는 시간을 측정하여 점수를 계산하며, 최소 0 점에 서 최대 1 점 사이의 점수가 산출된다. 1 에 가까울수록 유아가 자신의 행동을 잘 억제한다는 것을 의미한다.

Card Sorting 'Card Sorting'은 인지적 실행기능의 인지적 유연성을 측정한다. Card Sorting은 총 3단계로 이루어져있다. 1 단계는 색에 따라 파란색 배와 빨간색 토끼를 분류하는 것이 며, 2단계는 모양에 따라 나오는 카드를 분류한다. 마지막 3 단 계는 테두리가 있는 카드는 색에 따라 분류하고 테두리가 없 는 카드는 모양에 따라 분류하는 과제이다. 각 단계는 총 6 개 의 과제로 구성되어 있으며 1단계와 2단계에서 6 개 이상의 과 제를 수행하지 못하면 3단계를 수행할 수 없게 되어 있다. 총 점수는 0 점에서 최대 18 점의 점수가 산출되며 점수가 높을수 록 아동이 인지적 유연성을 가지고 있음을 의미한다.

CSBO CSBQ는 실행기능의 발달과 밀접한 관련이 있는 유 아의 자기 조절력과 사회성 발달을 측정하는 것으로, 총 33 개 의 항목으로 이루어져 있다. 각 항목은 응답자에게 사실이 아 님(1)에서 확실하게 사실인 경우(5)까지의 척도로 대상 행동 의 일반적 빈도를 평가하는 것이다. 이는 부모나 교사에 의해 보고되는 설문 형식의 앱이다. 
Expressive Vocabulary Expressive Vocabulary는 표현어휘 발달을 측정하는 어플리케이션이다. 유아는 화면의 그림을 보 고 무엇인지, 가리키고 있는 것은 무엇인지, 그 사람은 무엇을 하고 있는지를 대답하게 된다. 총 45 개의 항목으로 구성되어 있다. 6 개 항목을 연속으로 틀릴 경우 검사가 중단된다.

Early Numeracy 수, 공간, 측정, 수량, 서수, 기수(정수), 패 턴, 연산 등을 측정할 수 있는 수 발달 검사이다. 이 검사는 주 인공(로비 로봇)이 문제를 해결하도록 도움을 주는 형식으로, 유아가 과제들을 수행하도록 되어있다. 총 79장의 그림으로 이루어져 있으며, 5 개의 과제를 연속으로 틀릴 경우 검사가 중 단된다.

\section{유아의 실행기능, 어휘, 수 및 사회성 발달 측정 도구}

EYT의 준거타당도 검증을 위해 준거 도구로써 8개 상자과 제, 깃발 들기, 숫자 거꾸로 따라 말하기, 카드 분류(The Dimensional Change Card Sort [DCCS]), 표현어휘검사(Receptive Expressive Vocabulary Test-Expressive [REVT-E]), 유아그림수학 능력검사, 유아행동척도(Preschool and Kindergarten Behavior Scales [PKBS]) 총 7가지의 검사를 실시하였다(Table 2).

8개 상자과제 본 연구에서 시.공간 작업 기억을 측정하는 EYT Mr. Ant의 준거타당도 검증을 위해 '8개 상자과제' 도구를 시행하였다. 8개 상자과제는 Hughes (1998)가 개발한 것으로 색깔이 서로 다른 8 개의 상자 안에 사탕을 넣은 후 유아에게 상 자에 든 사탕을 모두 찾도록 하는 과제이다. 본 연구에서는 8 개의 색깔 상자와 그 안에 담긴 사탕 대신 쉽게 열어볼 수 있는 8 개의 색깔 종이컵과 당근 모형으로 대체하여 사용하였다.
8 개 상자과제는 목적 달성을 위해서 다단계적인 활동 계획 을 요구하지 않으나 시행중 자극-반응 간 지연 기간이 삽입되 며 상자의 색을 기억해야 한다는 전략을 자발적으로 생성하여 야 하는 검사이다(H. G. Park, 1999) 이에 자극-반응 간 지연기 간과 상자의 색을 기억하는 것을 통해 시·공간의 작업 기억 측 정에 적합하다고 판단하였다.

숫자 거꾸로 따라 말하기 본 연구에서는 음운론적 작업기억 을 측정하는 Not This의 준거타당도 검증을 위해 '숫자 거꾸로 따라 말하기'를 시행하였다. 숫자 거꾸로 따라 말하기는 인지 적 실행기능의 음운론적 작업 기억을 측정하는 도구이다. 1-9 까지의 숫자 중 일련의 숫자를 검사자가 불러주면 유아는 숫 자를 듣고, 들은 순서와 거꾸로 따라 말하는 검사이다. 두 자리 의 숫자부터 시작하여 한 자리씩 숫자가 늘어나게 되며, 같은 자리의 숫자는 '시행 1 과 2' 두 번씩 제시된다. 시행 한 개를 통 과할 때마다 1 씩을 얻게 되며, 시행 1 과 2 를 모두 틀릴 경우 검 사를 마친다. 본 검사는 음운론적 작업 기억을 측정하는 검사 이다.

숫자 거꾸로 따라 말하기는 필요한 정보를 유지하여 거꾸 로 되풀이하는 조정 과정을 동시에 처리해야 한다는 점에서 작업 기억 능력을 측정하기에 적합하다.

깃발 들기 본 연구에서는 실행 기능 중 행동적 측면의 억제 를 측정하는 $\mathrm{Go} / \mathrm{No}-\mathrm{Go}$ 의 준거타당도 검증을 위해 Y.-J. Lee, Lee와 Shin (2005)이 사용한 '깃발 들기' 과제를 사용하였다. 깃 발 들기 과제는 깃발을 들어 올리고 내리는 행동과 색에 대하 여 검사자가 명령한 내용과 반대로 행동을 통제하도록 요구하 는 것이다. 검사자가 유아에게 빨간 깃발과 파란 깃발을 제시 한 후, 처음에는 행동을 똑같이 따라하도록 정반응 과제를 설 명하고 6회 실시한다. 그리고 검사자의 명령과 반대(반대 방

Table 2

EYT's Evaluation Measure for Concurrent Validity

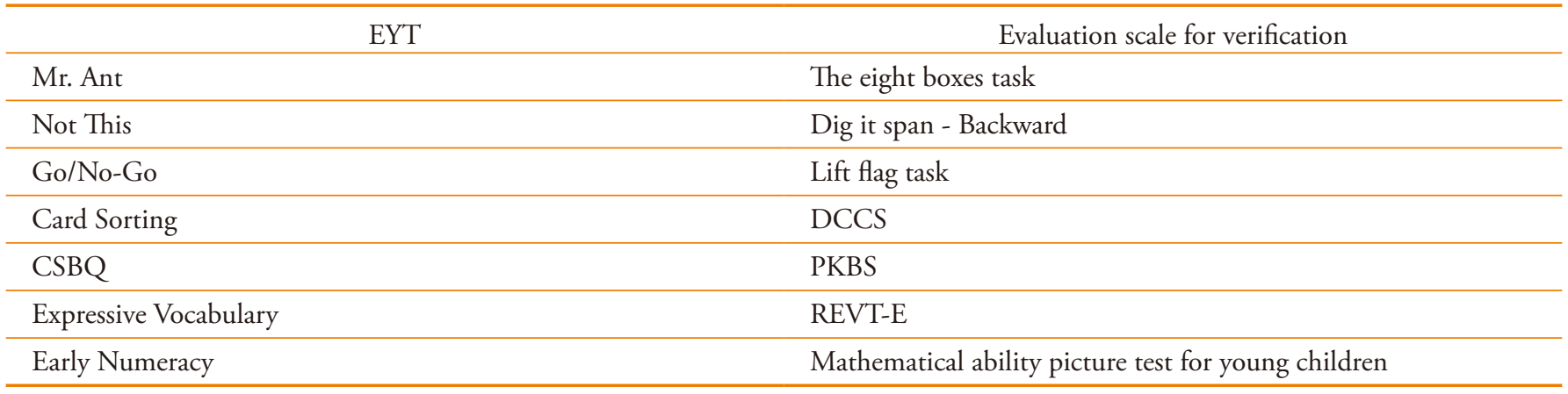


향, 반대 색깔)로 행동하도록 하는 역반응 과제를 설명하고 6 회 실시한다. 이처럼 깃발 들기 과제는 주어진 자극과 반대되 는 행동을 하도록 요구하는 것으로 인지억제 능력뿐만 아니라 우세한 행동을 억제하는 능력에도 중점을 둔 과제이다.

카드 분류(DCCS) 본 연구에서는 인지적 실행기능의 인지 적 유연성을 측정하는 Card Sorting의 준거타당도 검증을 위해 'DCCS' 과제를 사용하였다. DCCS는 인지적 유연성을 측정하 기 위한 검사로 빨간색 토끼와 파란색 배 그림이 하나씩 부착 되어 있는 두 개의 분류 상자를 제시한 후, 빨간색이나 파란색 의 배와 토끼 중 한 그림이 그려져 있는 카드를 유아에게 제시 하고 이를 색과 모양으로 구분하게 하도록 하는 과제이다. 총 세 단계로 진행되는데 첫 번째는 유아가 색 범주로 카드를 분 류하고, 두 번째는 모양 범주로, 세 번째는 앞의 두 가지 방법 을 포함한 테두리 범주가 추가되어 분류하게 된다. 유아의 인 지전환 능력을 측정하는 검사로 단계별로 두 번째 모양 분류 부터는 선행의 분류 범주(색)를 억제하여야 하고 세 번째 분류 에서는 모양과 색을 포함한 두 범주를 동시에 생각하여 억제 하도록 요구되는 과제이다.

DCCS는 한 가지 범주에 맞춰서 카드를 분류하는 유아에게 카드 분류를 멈추고 다른 범주에 맞춰서 카드를 분류하도록 연구자가 중간 지시를 하기 때문에 유아의 주의 전환 능력인 인지적 유연성을 살펴 볼 수 있다(Diamond, Carlson, \& Beck, 2005).

유아행동척도(PKBS) EYT의 'CSBQ'의 준거타당도를 측정 하기 위하여 'PKBS'를 검사도구로 사용하였다. PKBS는 3-6세 의 아동전기 아동들에서의 사회적 기술과 문제행동을 측정하 기 위해 구안된 행동평정척도이다. 이 척도는 사회적 기술 하 위척도 34 문항과 행동문제 하위척도 42 문항으로 구성되어 있 다. 사회적 기술 하위척도(social skill scale)는 사회적 협력성(12 문항), 사회적 상호작용(11문항), 사회적 독립성(11문항)이며 행동문제하위척도(problem behavior scale)는 외재적 행동문제 (자기중심성 11 문항, 행동과다 8 문항, 공격성 8 문항)와 내재적 행동문제(사회적 위축 7 문항, 불안 8 문항)로 구성되어 있다. 이 척도는 부모, 교사, 보육제공자들 또는 대상 아동의 행동을 자주 관찰한 사람들이 응답하도록 되어있다. 본 연구에서는 교사가 척도에 반응하도록 했다. 각 문항에 대해 교사가 아동 을 관찰한 데 근거하여 전혀 그렇지 않다(0점)에서 매우 그렇 다(5점)의 5점 Likert식 척도에 평정하였다.
표현어휘검사(REVT-E) EYT의 'Expressive Vocabulary'의 타 당도를 측정하기 위한 '표현어휘검사(REVT-E)'를 검사도구 로 사용하였다. REVT-E는 Y.-T. Kim, Lee, Hong, Kim과 Chang (2009)이 개발한 수용·표현 어휘력 검사(REVT) 중 표현어휘 에 대한 검사도구이다. 표현어휘 문항은 품사별로 명사 106 개, 동사 58 개, 형용사 및 부사 21 개로 총 185 문항으로 구성되 어 있다. 그리고 연령단계별로 나누어져 있으며 각 연령단계 별로 난이도를 고려하여 배열하였다. 이는 그림이름대기 검사 형태로, 그림을 보면서 검사자의 질문을 듣고 이에 해당하는 어휘를 이야기하는 방식이다. 연속적으로 8 개 문항 중 6 개를 틀리게 반응하면 검사를 중지한다.

유아그림수학능력검사 EYT의 'Early Numeracy'의 타당도 측 정 도구로 '유아그림수학능력검사'를 사용하였다. 유아그림수 학능력검사는 Choi와 Hwang (2003)이 개발한 검사로 총 4개 의 하위영역(사물의 규칙성, 수개념, 기하, 측정)으로 구성되 어 있다. 각 하위영역은 문항에 따라 구체물 조작을 통해 실시 하는 문항과 그림 자료를 이용한 문항으로 구성된다. 총 80 문 항의 검사도구로 대수는 분류, 서열, 패턴, 관계추론의 세부항 목으로 20 문항이고, 수개념은 수세기와 수연산에 관한 25 문 항으로 구성되어 있다. 기하는 도형과 공간개념에 관한 것으 로 20 문항이며, 측정은 시간과 측정의 개념으로 15 문항으로 되어 있다.

\section{연구절차}

본 연구의 절차는 한국판 번안과정과 내용타당도 확인과 구인 타당도, 공인타당도 검사 수행으로 나뉜다. 먼저, 검사도구의 번안을 위해 검사 개발자 Howard로부터 한국판 사용허가를 받아 EYT 어플리케이션의 스크립트를 번역하였고, 유아교사 포함 유아교육전공자 5 인과 검토하여 내용을 확정하였다. 또 한 직접 만 3-5세 유아에게 번역한 문장을 읽어주고 이해하는 데 어려움이 없는지 확인하였다. 번역한 스크립트는 전문 성 우가 녹음을 하여 오디오 파일로 만들었고, 이를 Howard에게 전달하여 아이패드 어플리케이션 한국어판 베타 버전을 제작 하였다.

EYT의 구인타당도와 공인타당도 검사를 위하여 검사를 실 시할 조사자를 모집하였다. 본 연구에 참여한 조사자는 총 6명 으로 모두 유아교육 관련 전공 석·박사 재학생이다. 조사자 간 의 신뢰도를 위해 자료 수집 전 두 차례 EYT 조사자 교육 및 준 거타당도 실험 실시 방법 교육을 진행하였으며, 조사가 실험진 
행 시 사용하는 발문, 조사자와 유아가 앉는 위치와 자세 및 반 응을 통제하여 유아에게 동일한 자극이 될 수 있도록 하였다.

구인타당도와 공인타당도를 구하기 위한 검사는 약 6주간 에 걸쳐 이루어졌다. 기관별로 학부모에게 $\mathrm{EYT}$ 타당화 연구 에 대한 설명문과 연구 참여 동의서를 배부하여 연구 참여 동 의를 구하였다. 연구 참여에 동의한 유아를 대상으로 $\mathrm{EYT}$ 검 사와 공인타당도를 확인하기 위한 검사를 각각 실시하였다. 유아는 교실이 아닌 기관 내 별도의 조용한 장소에서 조사자 와 함께 검사를 하였다. 조사자 간 어플리케이션 진행 순서는 불일치시켜, 유아 간 학습 효과가 일어나지 않도록 하였다. 검 사를 진행하는 동안 유아가 검사를 원하지 않을 경우, 조사자 는 세 번 격려한다(예: “다시 한 번 해 볼까?”). 그래도 유아가 원치 않을 경우, 검사를 즉시 중단하였다. 또한 하나의 어플리 케이션을 종료한 후, 다른 어플리케이션을 시작할 때 유아에 게 ‘다른 게임을 위해 잠시 기다려 줄 것' 에 대한 양해를 구한 뒤, 30초 이내에 다음 어플리케이션 검사를 시작 할 수 있도록 하였다. 또한 EYT 검사와 공인타당도를 확인하기 위한 검사 는 서로 영향을 미치지 않도록 3 일의 간격을 두고 시행하였다. 교사가 답하는 $\mathrm{CSBQ}$ 와 $\mathrm{PKBS}$ 는 교사에게 배포하여 1-2주 후 수거하였다.

\section{자료 분석}

EYT의 타당도와 신뢰도를 살펴보기 위한 자료 분석에는 STATA-MP 15.1 (Statacorp., College station, TX)을 사용하였다. 구인 타당도를 검증하고자 실시한 확인적 요인 분석에서는 실행기 능을 상위 영역으로 두고, 각각 시·공간적 작업 기억, 음운론적 작업 기억, 억제, 인지적 유연성을 측정하는 Mr. Ant, Not This, Go/No-Go, Card Sorting을 하위 영역으로 두었다. 각 영역 점수 는 표준화된 $z$-점수로 변환한 후 확인적 요인분석을 시행하고 그 적합성을 판별하기 위한 지표로는 8개 상자과제, 숫자 거꾸 로 따라 말하기, 깃발 들기, 카드 분류(DCCS)를 사용하였다. 나아가 실행기능을 나타내는 하위 요인들이 하나의 구인으로 엮일 수 있는지 확인하고자 4 개요인 간 상호상관계수를 산출 하였다. 또한 EYT 검사 중 아동의 응답 수준에 관계없이 검사 가 최종까지 진행되는 Go/No-Go 및 Expressive Vocabulary, 그리 고 교사에 의해 모든 문항의 답변이 이루어지는 CSBQ에 대해 서는 Cronbach's $\alpha$ 를 산출해 내적합치성을 검증하였다.

\section{Results}

\section{한국판 Early Years Toolbox (EYT)의 타당도}

\author{
한국판 EYT의 내용타당도
}

EYT의 내용타당도를 검증하기 위해 유아교육 전공 교수 1 명 과 영어권 국가 유학경험이 있는 유아교육학 박사과정 1 인 으로 구성된 전문가 집단이 번역내용을 검토하였다. 이들은 EYT 원 스크립트와 연구자가 한국어로 번안한 문장을 비교하 고 문장의 명확성, 유아의 실행기능, 언어, 수, 사회성 및 자기 조절력 측정의 적절성 그리고 한국문화에 대한 적절성을 검토 하였다. 또한 만 3-5세 유아에게 번역한 문장을 들려주어 이해 정도를 알아보았으며, 애매한 내용은 없는지 유아가 내용을 듣고 따라할 수 있는지 등을 확인하였다. 이러한 과정에서 유 아가 듣고 따라할 수 있는 지시문 선택의 문제, 교사가 응답하 는 $\mathrm{CSBQ}$ 의 문항의 적절성 논의가 이루어졌다. 한 예로 원 스 크립트에서는 'Point' 지시문을 “가리켜보세요."에서 “짚어보 세요."로 수정하는 작업이 이루어졌으며, $\mathrm{CSBQ}$ 의 문항의 경 우 “빈 공간을 응시한다."는 문항을 “먼 산을 바라본다."로 의 역하는 등의 수정 및 검토를 통해 유아와 교사의 이해를 높이 고자 하였다.

\section{한국판 EYT의 구인타당도}

한국판 EYT에서 4 개의 실행기능 하위요인들이 하나의 구인 으로 해석될 수 있는지 파악하고자 4 개 하위요인 간 상호상관 계수를 계산해 보았다. 그 결과는 Table 3과 같다.

Table 3에 제시된 바와 같이 EYT 하위요인 간 상관계수는 Mr. Ant와 Not This를 제외하고 .22 .41 ( $p<.05)$ 로 상호 정적 상관이 있는 것으로 나타나 하나의 구인으로 엮는 데 무리가 없음을 알 수 있다. 평가 도구의 타당성은 하위 요인 간 같은 변인을 측정해야 하는데, 본 도구는 유의미한 상관을 보여주 므로 이러한 요구를 충족시킨다고 볼 수 있다.

\section{한국판 EYT의 공인타당도}

EYT는 실행기능과 관련된 위 4개의 검사 외에 Expressive Vocabulary와 Early Numeracy, CSBQ 또한 검사한다. EYT 전반에 걸친 공인타당도를 살펴보기 위해 Table 4 와 같이 각 영역별 대응되는 면대면 검사를 시행하였다. 각 영역별로 상관계수를 
산출한 결과는 Table 5 와 같다.

Table 5와 같이, EYT 하위 요인과 각 준거 검사는 CSBQ만 을 제외하고 .19 .73으로 상호 정적인 상관이 있는 것으로 나 타난다 $(p<.05)$. 하지만 CSBQ는 PKBS와 유의한 관계가 나타 나지 않았다. $\mathrm{CSBQ}$ 와 $\mathrm{PKBS}$ 검사의 경우 유아 대상 면대면 검
사가 아닌 교사를 대상으로 한 설문을 진행하였다. 그러나 두 설문지에서 유아 당 점수를 확인한 결과 각 항목에 대한 유아 점수가 상이하였다. 따라서 현 시점에서는 $\mathrm{CSBQ}$ 를 제외하고 는 한국판 $\mathrm{EYT}$ 가 준거 검사와의 관계에 비추어 볼 때 타당도 가 높은 검사임을 제한적으로 확인할 수 있다.

Table 3

Correlation of EYT Executive Function Tests

\begin{tabular}{lccccc}
\hline & & Factor 1 & Factor 2 & Factor 3 & Factor 4 \\
\cline { 2 - 5 } & EYT & Mr. Ant & Go/No-Go & Not This & Card Sorting \\
\hline Factor 1 & Mr. Ant & - & $.41^{*}$ & .09 & $.32^{*}$ \\
Factor 2 & Go/No-Go & & $-34^{*}$ & $.35^{*}$ \\
Factor 3 & Not This & & & -2 \\
Factor 4 & Card Sorting & & & - \\
\hline
\end{tabular}

${ }^{*} p<.05 .{ }^{* *} p<.01$.

Table 4

EYT's Evaluation Measure for Concurrent Validity

\begin{tabular}{ll}
\hline \multicolumn{1}{c}{ EYT } & \multicolumn{1}{c}{ Evaluation scale for verification } \\
\hline Mr. Ant & The eight boxes task \\
Go/No-Go & Lift flag task \\
Not This & Dig it span - Backward \\
Card Sorting & DCCS \\
Expressive Vocabulary & REVT-E \\
Early Numeracy & Mathematical ability picture test for young children \\
CSBQ & PKBS \\
\hline
\end{tabular}

Table 5

Correlation of EYT and Evaluation Scale for Verification

\begin{tabular}{|c|c|c|c|}
\hline & EYT & Evaluation scale for verification & Correlation coefficient \\
\hline Mr. An & & The eight boxes task & $.19^{*}$ \\
\hline $\mathrm{Go} / \mathrm{No}$ & & Lift flag task & $.28^{*}$ \\
\hline Not Th & & Dig it span - Backward & $.27^{*}$ \\
\hline Card Sc & ting & DCCS & $.57^{*}$ \\
\hline Express & e Vocabulary & REVT-E & $.66^{*}$ \\
\hline Early N & meracy & Mathematical ability picture test for young children & $.73^{*}$ \\
\hline CSBQ & Sociality & Social skill & .10 \\
\hline & Prosocial behavior & & .09 \\
\hline & Behavioral self regulation & & .05 \\
\hline & Cognitive self regulation & & .09 \\
\hline & Emotional self regulation & & .05 \\
\hline CSBQ & Externalizing behavior problem & Behavior problem & .03 \\
\hline & Internalizing behavior problem & & .07 \\
\hline
\end{tabular}

${ }^{*} p<.05$. 
Table 6

Cronbach's a of Go/No-Go, Expressive Vocabulary, CSBQ

\begin{tabular}{|c|c|c|c|}
\hline & Scale & Number of test & Cronbach's $\alpha$ \\
\hline \multicolumn{2}{|l|}{ Go } & 60 & .92 \\
\hline \multicolumn{2}{|l|}{ No-Go } & 15 & .77 \\
\hline \multirow[t]{5}{*}{ CSBQ } & Sociality & 7 & .84 \\
\hline & Prosocial behavior & 5 & .87 \\
\hline & Emotional self regulation & 6 & .81 \\
\hline & Externalizing behavior problem & 5 & .76 \\
\hline & Internalizing behavior problem & 5 & .82 \\
\hline
\end{tabular}

\section{한국판 EYT의 신뢰도}

ETY 중 유아의 응답 수준에 관계없이 검사가 최종까지 진행되 는 $\mathrm{Go} / \mathrm{No}-\mathrm{Go}$ 및 Expressive Vocabulary 그리고 교사에 의해 모든 문항의 답변이 이루어지는 CSBQ에 대해서는 Cronbach's $\alpha$ 를 산출해 내적합치성을 검증하였다. 그 결과는 Table 6 과 같다.

Table 6을 보면 각 요인별 신뢰도 계수는 .76 .92 수준으로 나타났다. $\mathrm{Go} / \mathrm{No}-\mathrm{Go}$ 검사의 경우 $\mathrm{Go}$ 검사는 $.92, \mathrm{No}-\mathrm{Go}$ 검 사는 .77이며, Expressive Vocabulary 검사는 .80으로 드러났다. $\mathrm{CSBQ}$ 검사의 경우 각 하위 항목별로 사회성 .84, 친사회적 행 동 .87 , 행동 자기 조절 .88 , 인지 자기조절 . 79 , 정서 자기 조절 . 81, 외현화 문제 .76, 내재화 문제 .82로 나타났다. 각 영역별 신뢰도 계수가 모두 .7 이상으로 나타나 각 영역별 문항 구성 에 내적 일관성이 있음을 알 수 있다.

\section{Discussion}

본 연구는 한국판 Early Years Toolbox (EYT)의 타당화를 목적 으로 타당화 작업과 신뢰도 평가가 이루어졌다. 연구를 통해 나타난 결과를 중심으로 논의하면 다음과 같다.

첫째, EYT의 타당도를 알아보기 위해 내용타당도, 구인타 당도, 공인타당도를 살펴보았다. 먼저 본 연구 EYT의 내용타 당도는 전문가 집단의 번역된 스크립트 확인과 만 3-5세 유아 를 대상으로 스크립트 이해도를 파악하여 유아와 교사가 이해 하기 쉽게 의역 및 번역하여 확보되었다.

또한 실행기능을 측정하는 4개의 도구(Mr. Ant, Not This, Go/No-Go, Card Sorting)의 상관을 구해 하나의 구인으로 묶
일 수 있는지 구인타당도를 구하였다. 그 결과 각 도구는 상 호 정적 상관 $(r=.22 \sim .44, p<.05)$ 이 있는 것으로 나타나 하나 의 구인으로 엮는데 무리가 없음을 알 수 있다. 이는 Howard 와 Mellhuish (2017)의 연구에서 각 검사 간 정적 상관 $(r=.23$ $\sim .57, p<.05)$ 이 있는 것으로 나타난 것과 비슷한 양상으로, 한국판 EYT의 구조를 지지하였다. Not This와 Card Sorting 의 경우, $.22(p<.01)$ 수준에서 유의미한 상관을 보였다. 보통 상관이 .30 .70 사이에 있어야 판별타당성이 확보되었다고 볼 수 있으나, 호주 유아를 대상으로 한 Howard와 Mellhuish (2017)의 연구에서도 .23 ( $p<.05)$ 의 상관관계가 있는 것으로 미루어 보아 한국판 EYT의 구조를 지지하는 데 큰 문제가 없 을 것으로 보인다.

다만, Mr. Ant와 Not This의 경우 유의미한 상관이 나타나지 않았다. 호주 유아를 대상으로 한 Howard와 Mellhuish (2017) 의 EYT 타당화 연구에서는 Mr. Ant 와 Not This의 상관이 .28 $(p<.05)$ 로 나타난 것과 차이가 있다. 이는 $\mathrm{Mr}$. Ant가 시각적 작업 기억을 측정하는 것이라면, Not This는 음운론적 작업 기 억을 측정하는 것이다. 그러나 측정하는 방식이 비슷하고 한 유아가 한 번에 7 개의 어플리케이션을 실시하는 본 연구의 조 사 방식으로 인해 유아의 검사 피로도가 점수에 영향을 미쳤 을 것으로 예상된다. 이에 추후 연구에서는 유아의 검사 피로 도를 줄일 수 있는 방향으로 하루 검사 어플리케이션의 수를 제한하여 실시해 볼 필요성이 제기된다.

다음으로, 한국판 $\mathrm{EYT}$ 의 공인타당도를 검증하기 위하여 한국에서 실행기능을 측정할 때 가장 대중적으로 사용되는 검 사를 준거로 삼아 관련성을 살펴보았다. Mr. Ant와 8개의 상자 $(r=.19, p<.05), \mathrm{Go} / \mathrm{No}-\mathrm{Go}$ 와 깃발 들기 $(r=.28, p<.05)$, Not This와 숫자 거꾸로 따라 말하기 $(r=.27, p<.05)$, Card Sorting 
과 카드 분류 $(r=.57, p<.05)$, Expressive Vocabulary와 REVT-E $(r=.66, p<.05)$, Early Numeracy와 유아그림수학능력검사 $(r=$ $.73, p<.05)$ 는 모두 유의한 상관이 나타났다. 이는 호주 아동 으로 대상으로 실시된 $\mathrm{EYT}$ 검사의 공인타당도의 결과 $(r=.42$ $\sim .60, p<.05)$ 를 지지하고 있다. 다만, CSBQ와 PKBS간의 상 관은 확인할 수 없었다. CSBQ는 유아의 사회성, 친사회적 행 동, 행동 자기 조절, 인지 자기조절, 정서 자기 조절, 외현화 문 제, 내재화 문제로 하위 영역이 나뉘어 있다. 반면, PKBS는 사 회적 기술과 문제 행동으로 크게 2 개의 하위 영역으로 구성되 어 그 내용이 아주 유사하지 않았을 것으로 보여 진다. 또한 교 사가 한 아동에 대한 응답으로 CSBQ 39문항, PKBS 76문항 총 115 문항에 답을 하게 되었다. 이에 교사가 응답에 대한 피 로도로 인하여 정확한 응답을 하지 않았을 가능성도 제기된 다. 특히, Howard와 Mellhuish (2017)의 연구에서는 CSBQ가 다른 사회성 발달 검사인 $\mathrm{SDQ}$ 와 매우 높은 상관 $(r=.78 \sim .91$, $p<.001)$ 이 나타난다. 따라서 한국판 $\mathrm{CSBQ}$ 를 보다 관련성 있 는 척도를 이용하여 교사들의 피로도를 덜 수 있는 방법으로 다시 타당화를 검증해 볼 필요가 제기된다. 이상으로 한국판 $\mathrm{EYT}$ 검사 간 상관과 여타 다른 도구와의 관련성을 통해 도출 된 결과를 종합하면 $\mathrm{CSBQ}$ 를 제외한 $\mathrm{EYT}$ 검사의 검사는 타당 함을 알 수 있다.

둘째, EYT의 신뢰도를 알아보기 위해 내적 합치도 계수 Cronbach's $\alpha$ 를 산출하였다. 신뢰도 계수는 유아의 응답 수준 에 따라 차이가 없이 검사가 끝까지 이루어지는 Go/No-Go, Expressive Vocabulary 그리고 교사가 응답하는 CSBQ에 한하 여 살펴보았다. $\mathrm{Go} / \mathrm{No}-\mathrm{Go}$ 의 경우 $\mathrm{Go}$ 검사 (Cronbach's $\alpha=.92)$ 와 No-Go 검사(Cronbach's $\alpha=.77)$ 는 매우 높은 내적 합치도 가 나타났다. 또한 Expressive Vocabulary 역시 우수한 내적 합치 도(Cronbach's $\alpha=.80$ )를 보여준다. CSBQ의 경우 각 하위요인 별로 차이는 있는 모두 우수한 내적 합치도(Cronbach's $\alpha=.76$ .88)가 나타났다. 이는 Howard와 Mellhuish (2017)가 실시한 연구에서 나타난 검사간 내적 일치도 계수, $\mathrm{Go} / \mathrm{No}-\mathrm{Go}$ 중 $\mathrm{Go}$ .95, No-Go .84, Expressive Vocabulary .92, CSBQ .74 .89와 일 관된 결과를 보여준다. 이로써 한국판 EYT가 신뢰로운 도구 임을 알 수 있다.

이상의 결과들을 통해 한국판 EYT는 국내 유아를 대상으 로 실행기능, 언어, 수를 측정하기에 신뢰할만하고 타당한 도 구임을 확인할 수 있었다. 또한 본 연구는 실행기능 도구 타당 화 연구물 축적에 기여하고, 실행기능을 측정하고자 하는 연 구에 방향성을 제시하였다. 이러한 맥락에서 인생을 살아가는 기술을 습득할 때 중요하게 여겨야 할 실행기능을 측정할 수
있는 저렴하고 간편한 도구를 제공함으로써 유아 실행기능 연 구가 수행될 수 있도록 기초자료를 제공하였다는 데 그 의의 가 있다. 또한 EYT는 영어뿐만 아니라 일본어, 포르투갈어, 스 웨덴어, 덴마크어, 인도네시아어, 남아프리카공화국 공식어 (줄루어, 코사어, 소토어 등) 여러 언어로 번역되어 사용되고 있다. 따라서 추후 다른 나라 유아와의 실행기능 비교 연구와 같은 국제 비교연구가 가능하다는 점에서 의의가 있다.

이러한 의의에도 불구하고 본 연구의 제한점은 다음과 같 다. 첫째, 본 연구에서 어린이집과 유치원 만 3 세 만 5 세 유 아를 고르게 표집하였으나, 각 집단별로 충분한 표본수를 확 보하지는 못하였다. 또한 본 연구에서는 편의표집을 통해 연 구대상을 확보하여 한 지역에 국한하여 연구가 이루어진 경향 이 있다. 따라서 후속연구에서는 다양한 지역과 충분한 표본 수를 확보한 분석이 필요하다. 둘째, $\mathrm{CSBQ}$ 의 선행연구에서는 다른 사회성 검사와의 매우 높은 상관이 나타났으나 본 연구 에서는 $\mathrm{CSBQ}$ 와 $\mathrm{PKBS}$ 의 상관이 나타나지 않았다. 이에 한국 에서 많이 사용되는 다른 도구를 통해 $\mathrm{CSBQ}$ 의 타당화 작업이 이루어져야 할 것이다.

\section{Conflict of Interest}

No potential conflict of interest relevant to this article was reported.

\section{References}

\section{In English}

Bailey, C. E. (2007). Cognitive accuracy and intelligent executive function in the brain and in business. Annals of the New York Academy of Sciences, 1118(1), 122-141. doi:10.1196/ annals. 1412.011

Bernier, A., Carlson, S. M., Deschênes, M., \& Matte-Gagné, C. (2012). Social factors in the development of early executive functioning: A closer look at the caregiving environment. Developmental Science, 15(1), 12-24. doi:10.1111/j.14677687.2011.01093.x

Blair, C., \& Razza, R. P. (2007). Relating effortful control, executive function, and false-belief understanding to emerging math and literacy ability in kindergarten. Child Development, 78(2), 647-663. doi:10.1111/j.14678624.2007.01019.x 
Blair, C., Zelazo, P. D., \& Greenberg, M. (2005). The measurement of executive function in early childhood. Developmental Neuropsychology, 28(2), 561-571. doi:10.1207/s15326942 dn2802_1

Borella, E., Carretti, B., \& Pelegrina, S. (2010). The specific role of inhibition in reading comprehension in good and poor comprehenders. Journal of Learning Disabilities, 43(6), 541552. doi:10.1177/0022219410371676

Cunningham, W. A., \& Zelazo, P. D. (2007). Attitudes and evaluations: A social cognitive neuroscience perspective. Trends in Cognitive Sciences, 11(3), 97-104. doi:10.1016/ j.tics.2006.12.005

Davis, J. C., Marra, C. A., Najafzadeh, M., \& Lui-Ambrose, T. (2010). The independent contribution of executive functions to health related quality of life in older women. BMC Geriatrisc, 10, 16-23. doi:10.1186/1471-2318-10-16

Diamond, A. (2013). Executive functions. Annual Review of Psychology, 64, 135-168. doi:10.1146/annurev-psych113011-143750

Diamond, A., Barnett, W. S., Thomas, J., \& Munro, S. (2007). Preschool program improves cognitive control. Science, 318(5855), 1387-1388. doi:10.1126/science.1151148

Diamond, A., Carlson, S. M., \& Beck, D. M. (2005). Preschool children's performance in task switching on the dimensional change card sort task: Separating the dimensions aids the ability to switch. Developmental Neuropsychology, 28(2), 689-729. doi:10.1207/s15326942dn2802_7

Gerstadt, C. L., Hong, Y. J., \& Diamond, A. (1994). The relationship between cognition and action: Performance of children 3127 years old on a stroop-like day-night test. Cognition, 53(2), 129-153. doi:10.1016/0010-0277(94)90068-X

Howard, S. J., \& Melhuish, E. (2017). An early years toolbox for assessing early executive function, language, selfregulation, and social development: Validity, reliability, and preliminary norms. Journal of Psychoeducational Assessment, 35(3), 255-275. doi:10.1177/0734282916633009

Howard, S. J., \& Okely, A. D. (2015). Catching fish and avoiding sharks: Investigating factors that influence developmentally appropriate measurement of preschoolers' inhibitory control. Journal of Psychoeducational Assessment, 33(6), 585596. doi:10.1177/0734282914562933

Hughes, C. (1998). Executive function in preschoolers: Links with theory of mind and verbal ability. British Journal of Developmental Psychology, 16, 233-253. doi:10.1111/ j.2044-835X.1998.tb00921.x

Kessels, R. P. C., Van Zandvoort, M. J. E., Postma, A., Kappelle, L. J., \& De Haan, E. H. F. (2000). The corsi blocktapping task: Standardization and normative data. Applied Neuropsychology, 7(4), 252-258. doi:10.1207/ S15324826AN0704_8
Kochanska, G., Murray, K., Jacques, T. Y., Koenig, A. L., \& Vandegeest, K. A. (1996). Inhibitory control in young children and its role in emerging internalization. Child Development, 67(2), 490-507. doi:10.1111/j.1467-8624. 1996.tb01747.x

McGlamery, M. E., Ball, S. E., Henley, T. B., \& Besozzi, M. (2007). Theory of mind, attention, and executive function in kindergarten boys. Emotional and Behavioral Difficulties, 12(1), 29-47. doi:10.1080/13632750601135899

Morrison, F. J., Ponitz, C. C., \& McClelland, M. M. (2010). Selfregulation and academic achievement in the transition to school. In S. D. Calkins, \& M. A. Bell (Eds.), Human brain development. Child development at the intersection of emotion and cognition (pp. 203-224). Washington, DC: American Psychological Association. doi:10.1037/12059011

Peake, P. K., Hebl, M., \& Mischel, W. (2002). Strategic attention deployment for delay of gratification in working and waiting situations. Developmental Psychology, 38(2), 313326. doi:10.1037/0012-1649.38.2.313

Riggs, N. R., Blair, C. B., \& Greenberg, M. T. (2003). Concurrent and 2-year longitudinal relations between executive function and the behavior of 1 st and 2 nd grade children. Child Neuropsychology, 9(4), 267-276. doi:10.1076/ chin.9.4.267.23513

Sethi, A., Mischel, W., Aber, J. L., Shoda, Y., \& Rodriguez, M. L. (2000). The role of strategic attention deployment in development of self-regulation: Predicting preschoolers' delay of gratification from mother-toddler interactions. Developmental Psychology, 36(6), 767-777. doi:10.1037/0012-1649.36.6.767

STATA-MP 15.1 [Computer software]. College station, Texas: Statacorp.

Stroop, J. R. (1935). Studies of interference in serial verbal reactions. Journal of Experimental Psychology, 18(6), 643662. doi:10.1037/h0054651

Welsh, M. C., \& Pennington, B. F. (1988). Assessing frontal lobe functioning in children: Views from developmental psychology. Developmental Neuropsychology, 4(3), 199-230. doi:10.1080/87565648809540405

Zelazo, P. D. (2006). The Dimensional Change Card Sort (DCCS): A method of assessing executive function in children. Nature Protocols, 1(1), 297-301. doi:10.1038/nprot.2006.46

Zelazo, P. D., \& Muller, U. (2004). Executive function in typical and atypical development. In U. Goswami (Ed.), Handbook of childhood cognitive development (pp. 445-469). Oxford: Blackwell Publishing. doi:10.1002/9780470996652.ch20

\section{In Korean}

Cha, K. (2015). Maternal interaction behaviors and the development 
of executive functions among Korean preschoolers. Journal of Early Childhood Education, 35(2), 117-141.

Chi, S.-A., \& Baik, J.-H. (2016). An analysis of the self-esteem related variables on young children: Focused on cool executive function, hot executive function and mother's adult attachment. Journal of Early Childhood Education, 36(6), 53-76. doi:10.18023/ kjece.2016.36.6.003

Chi, S.-A., \& Kim, C. (2016). An analysis on attention ability related variables of young children: A focus on executive function, language ability, self-esteem, and recoveryresilience. Early Childhood Education Research \& Review, 20(6), 235-261.

Choi, H.-J., \& Hwang, H.-I. (2003). The development of a mathematical ability test for young children. Journal of Early Childhood Education, 23(4), 273-295.

Do, R., Cho, S.-C., Kim, B.-N., Kim, J.-W., \& Shin, M.-S. (2010). Development of executive function in childhood. The Journal of the Korean Association of Psychotherapy, 2(2), 1-12.

Kim, H.-J., \& Hong, S.-O. (2011). A comparison of executive function between gifted and non-gifted young children. The Journal of Korean Open Association for Early Childhood Education, 16(3), 259-280.

Kim, Y.-M. (2018). The development of children's hot and cool executive function and relationship between language ability. Journal of Future Early Childhood Education, 25(3), 131-157. doi:10.22155/JFECE.25.3.131.157

Kim, Y.-T., Lee, J.-Y., Hong, G.-H., Kim, K.-H., \& Chang, H.-S. (2009). Validity of the receptive and expressive vocabulary test on preschool children with language delay. Journal of Speech-Language \& Hearing Disorders, 18(1), 57-72.

Kong, Y.-S., \& Lim, J.-Y. (2013). The effects of temperament and executive function on preschooler's externalizing and internalizing problems: Focusing on testing Latzman's problem behavior theory. The Journal of Child Education, 22(4), 5-24.

Lee, K., \& Lee, J. (2017). The effects of young children's executive function on mathematical problem-solving ability. Journal of Children's Literature and Education, 18(1), 311-334. doi:10.22154/JCLE.18.1.14

Lee, Y.-J., Lee, J., \& Shin, E.-S. (2005). The effects of picture story based group game play activities on young children's emotional intelligence, theory of mind, and executive function. Journal of Early Childhood Education, 25(3), 119147.

Lee, W., \& Cheung, E. J. (2018). Influences of children's age and executive function on analogical reasoning and evidential reasoning. Journal of Korean Council for Children \& Rights, 22(2), 301-317. doi:10.21459/kccr.2018.22.2.301

Park, K.-S. (2018). The influence of temperament, executive function and maternal emotional expressiveness on the social competence of infants (Doctoral dissertation). Retrieved from http:// www.riss.kr/link?id=T14668227

Pahk, H. G. (1999). A neuropsychological study of executive function deficits in autistic disorder (Master' thesis). Retrieved from http://www.riss.kr/link?id=T8424050

Shin, E.-S. (2005). Relationships among theory of mind, decontexutlization in pretend play, language, executive function, and central coherence in young children. Journal of Early Childhood Education, 25(1), 65-90.

Song, M., \& Ha, E. (2014). The effects of children's executive function impairments and ADHD symptoms on selfdirected learning capability. Korean Journal of Play Therapy, 17(2), 193-207.

Sung, J. (2017). The effects of maternal instructional support, teacher-child, relationship, and children's cool and hot executive functions on children's task-focused behaviors. The Korean Journal of Developmental Psychology, 30(1), 195-217.

\section{ORCID}

Shunah Chung

Inkyung Kim

Heejin Kim

Yumi Ma

Boyoung Park https://orcid.org/0000-0001-7812-4706 https://orcid.org/0000-0002-3003-9825 https://orcid.org/0000-0003-2874-4557 https://orcid.org/0000-0001-7829-0448 https://orcid.org/0000-0002-4692-8395
Received October 31, 2018

Revision received December 7, 2018

Accepted December 13, 2018 